\title{
Computer evaluation of the influence of liquid metal movements on defects formation in the casting
}

\author{
Leszek Sowa ${ }^{1, *}$, Tomasz Skrzypczak $^{1}$, and Pawet Kwiatoń ${ }^{1}$ \\ ${ }^{1}$ Czestochowa University of Technology, Institute of Mechanics and Machine Design Fundamentals, \\ Dąbrowskiego 73, 42-201 Częstochowa, Poland
}

\begin{abstract}
This paper concerns the modelling of the solidification process including the phenomena of heat transfer and fluid flow during the initial stage of the metal casting process. During this period, the molten metal motions have an essential influence on solidification kinetics. An analysis of solidification kinetics, by determining the velocity and temperature fields in a system of riser-casting was made. Velocity fields were obtained by solving the momentum equations and the continuity equation, while the thermal fields were obtained by solving the conduction equation containing the convection term. After completion of the filling process the main solidification of molten metal takes place and its shrinkage. The phenomenon of casting shrinkage cannot be avoided, but it is possible to minimize its negative effects on the casting quality. One with ways to solve this problem is to design the mould in such a way that the solidification proceeds in accordance to the assumed direction and finished in the riser. Generally, the aim of search is to obtain a casting without shrinkage defects.
\end{abstract}

Keywords: numerical modelling, solidification, casting defect, molten metal flow

\section{Introduction}

Producing a casting the high quality is not easy to achieve, hence the need for continuous improvement of casting methods. The work analysed the formation of a casting by gravitational pouring of molten metal into a metal mould, but the development of other casting methods has recently been devoted a lot of attention, mainly continuous casting $[1,2]$ or the lost-wax casting technology [3]. Direct examining of the phenomena occurring during the casting process is difficult due to the lack of optical access and high temperature, which is why computer simulation seems to be a good solution to this problem [1, 2, 4-12]. In order to obtain an effective numerical solution to the problem under investigation, the number of analysed phenomena should be limited to the most important ones which have a

\footnotetext{
* Corresponding author: sowa@imipkm.pcz.pl

Reviewers: Janusz Mielniczuk, Radim Halama
} 
direct impact on the quality of the casting. In this paper, the casting solidification process is mainly analysed taking into account the heat transfer and fluid flow phenomena in the initial stage of casting process of the cast steel in a metal mould. During this period, the molten metal motions have an essential influence on solidification kinetics. This requires the formulation of adequate mathematical model that takes into account the mutual influence of thermal and flow phenomena in the process of filling the cavity of the casting mold and after its completion [2, 4-7]. Some researchers neglect in the numerical analysis of the casting process the period of filling the mold cavity with liquid metal, assuming as the initial condition for the numerical calculation that the mould cavity is fully filled [8-11]. Other researchers in turn, focus in their research on the analysis of the formation and evolution of a shrinkage cavity or other defects of the casting process [3, 10-12].

Numerous numerical simulations of the solidification process with or without taking into account liquid metal movements were performed in the work. Velocity and temperature fields were obtained, which were analysed in subsequent steps of time by tracking the position of solidus isotherm that limits the solid-liquid area and observing whether it is not closed. If this situation occurs in some place in the casting, then the supply of liquid phase to this place will be interrupted and a shrinkage cavity may form here or a macroporosity area may arise. The resulting shrinkage defects can eliminate the casting from its use. We try to prevent such a situation choosing of the riser with appropriate shapes and dimensions, so that the process of solidification ends in it. The arising the unavoidable shrinkage defect in the riser allows to obtain a casting without any defects, what we strive for when designing the mould. Therefore, the purpose of this work was to select the appropriate dimensions of the riser to the solidifying casting in a metal mould, so that it was created without shrinkage defects, and investigating of the influence of molten metal movements on the location of the shrinkage cavity in the final moment solidification of the casting.

\section{The mathematical model of the casting solidification taking into account the liquid metal movements}

The mathematical model for the computer simulation of solidification gives consideration to both the movements of metal liquid phase during the mould cavity filing process and convective movements after pouring was proposed. It was assumed that the solidification front is mushy. The mathematical model is based on solving the following system of equations in a cylindrical axisymmetric coordinate system [2, 4-10]:

- the Navier-Stokes equations:

$$
\begin{aligned}
& \mu\left(\frac{\partial^{2} v_{r}}{\partial r^{2}}+\frac{1}{r} \frac{\partial_{r}}{\partial r}+\frac{\partial^{2} v_{r}}{\partial z^{2}}-\frac{v_{r}}{r^{2}}\right)-\frac{\partial p}{\partial r}+\rho g_{r} \beta\left(T-T_{\infty}\right)+\rho g_{r}=\rho \frac{d v_{r}}{d t} \\
& \mu\left(\frac{\partial^{2} v_{z}}{\partial r^{2}}+\frac{1}{r} \frac{\partial v_{z}}{\partial r}+\frac{\partial^{2} v_{z}}{\partial z^{2}}\right)-\frac{\partial p}{\partial z}+\rho g_{z} \beta\left(T-T_{\infty}\right)+\rho g_{z}=\rho \frac{d v_{z}}{d t}
\end{aligned}
$$

- the continuity equation:

$$
\frac{\partial_{r}}{\partial r}+\frac{v_{r}}{r}+\frac{\partial_{z}}{\partial z}=0
$$

- the heat conduction equation containing the convection term: 


$$
\frac{\lambda}{r} \frac{\partial T}{\partial r}+\frac{\partial}{\partial r}\left(\lambda \frac{\partial T}{\partial r}\right)+\frac{\partial}{\partial z}\left(\lambda \frac{\partial T}{\partial z}\right)-\rho C_{e f}\left(v_{r} \frac{\partial T}{\partial r}+v_{z} \frac{\partial T}{\partial z}\right)-\rho C_{e f} \frac{\partial T}{\partial t}=0
$$

- the volume fraction equation:

$$
\frac{\partial F}{\partial t}+v_{r} \frac{\partial F}{\partial r}+v_{z} \frac{\partial F}{\partial z}=0
$$

where: $T$ is the temperature $[\mathrm{K}], t$ is the time $[\mathrm{s}], \rho=\rho(T)$ is the density $\left[\mathrm{kg} / \mathrm{m}^{3}\right], \lambda$ is the thermal conductivity coefficient $[\mathrm{W} /(\mathrm{mK})], v_{r}, v_{z}$ are the $r$-component and $z$-component of velocity, respectively $[\mathrm{m} / \mathrm{s}], \mu(T)$ is the dynamical viscosity coefficient $[\mathrm{kg} /(\mathrm{ms})]$, $C_{e f}=c+L /\left(T_{L}-T_{S}\right)$ is the effective specific heat of a mushy zone $[\mathrm{J} /(\mathrm{kgK})], L$ is the latent heat of solidification $[\mathrm{J} / \mathrm{kg}], c$ is the specific heat $[\mathrm{J} /(\mathrm{kgK})], p$ is the pressure $\left[\mathrm{N} / \mathrm{m}^{2}\right], g_{r}, g_{z}$ are the $r$ - and $z$-component of gravitational acceleration, respectively $\left[\mathrm{m} / \mathrm{s}^{2}\right], \beta$ is the volume coefficient of thermal expansion $[1 / \mathrm{K}], r, z$ are the coordinates of the vector of the considered node's position $[\mathrm{m}], T_{\infty}$ is the reference temperature $\left(T_{\infty}=T_{\text {in }}\right)[\mathrm{K}], r$ is the radius $[\mathrm{m}]$ and $F$ is the pseudo-concentration function, which is defined as a continuous function varying between 0 and 1 across the element lying on the free surface.

The set of equations (1-4) is completed by the appropriate initial conditions and the boundary conditions.

The initial conditions for velocity field and temperature fields are given as $[2,5,7-10]$ :

$$
\mathbf{v}\left(r, z, t_{0}\right)=\mathbf{v}_{0}(r, z)=\left.v_{i n}\right|_{\Gamma_{1-1}}, \quad T\left(r, z, t_{0}\right)=T_{0}(r, z)= \begin{cases}T_{i n} & \text { on } \Gamma_{1-1} \\ T_{A} & \text { in } \Omega_{A}, \\ T_{M} & \text { in } \Omega_{M}\end{cases}
$$

The boundary conditions, on the indicated surfaces (Fig. 1), specified in the considered problem were as follows:

- for velocity $[2,5,7-9]$ :

$$
\begin{array}{ll}
\left.v_{n}\right|_{\Gamma_{1-1}}=v_{i n}, & \left.v_{t}\right|_{\Gamma_{1-1}}=\left.v_{t}\right|_{\Gamma_{2-2}}=\left.v_{n}\right|_{\Gamma_{2-2}}=0, \\
\left.v_{n}\right|_{r=0}=0, & \left.v_{n}\right|_{\Gamma_{G}}=0,\left.\quad v_{t}\right|_{\Gamma_{G}}=0,\left.\quad \frac{\partial v_{t}}{\partial n}\right|_{r=0}=0,
\end{array}
$$

- for temperature $[2,5,7-12]$ :

$$
\begin{array}{cc}
\left.T\right|_{\Gamma_{1-1}}=T_{i n}, & \left.\frac{\partial T}{\partial n}\right|_{r=0}=0, \\
\left.\frac{\partial T}{\partial n}\right|_{\Gamma_{2-2}}=0, & \left.\lambda_{M} \frac{\partial T_{M}}{\partial n}\right|_{\Gamma_{M}}=-\alpha_{M}\left(\left.T_{M}\right|_{\Gamma_{M}}-T_{a}\right), \\
\left.\lambda_{S} \frac{\partial T_{S}}{\partial n}\right|_{\Gamma_{G-}}=\left.\lambda_{G} \frac{\partial T_{G}}{\partial n}\right|_{\Gamma_{G-}}, & \left.\lambda_{G} \frac{\partial T_{G}}{\partial n}\right|_{\Gamma_{G+}}=\left.\lambda_{M} \frac{\partial T_{M}}{\partial n}\right|_{\Gamma_{G+}},
\end{array}
$$

where: $T_{a}$, is the ambient temperature $[\mathrm{K}], T_{A}$ is the air temperature inside mould cavity in initial state $[\mathrm{K}], \alpha_{M}$ is the heat-transfer coefficient between a mould and ambient 
$\left[\mathrm{W} /\left(\mathrm{m}^{2} \mathrm{~K}\right)\right], T_{M}, T_{S}, T_{G}$ are the temperature of mould, solid phase and gap (protective coating), respectively $[\mathrm{K}], T_{\text {in }}$ is the initial temperature $[\mathrm{K}], \lambda_{M}, \lambda_{G}, \lambda_{S}$ are the thermal conductivity coefficient of mould, gap and solid phase, respectively $[\mathrm{K}], v_{\text {in }}$ is the initial velocity $[\mathrm{m} / \mathrm{s}], v_{n}, v_{t}$ are the normal component and tangential component of velocity vector, respectively $[\mathrm{m} / \mathrm{s}]$ and $\boldsymbol{n}$ is the outward unit normal surface vector.

In the applied model of solid phase growth, the internal heat sources are not come evident in the equation of heat conductivity (3), because they are in the effective specific heat of the mushy zone $[2,7-10]$. The above equations were solved by the finite element method in the weighted residuals formulation [2, 5, 7-10]. In the numerical simulations, coupling of the thermal and flow phenomena by change in the thermophysical parameters of metals alloy depending on the temperature, has been taken into consideration.

\section{Description of the problem}

To analyse the influence of moving molten metal alloy and riser size on the casting solidification, the system of casting-mould shown in Figure 1 was considered. Calculations of the heat transfer were made for the overall system of casting-riser-mould-ambient. The overall dimensions of the steel mould are equal to: $d=0.320 \mathrm{~m}, h=0.280 \mathrm{~m}$, while dimensions of the mould cavity are equal to: $d_{o}=0.200 \mathrm{~m}, h_{o}=0.070 \mathrm{~m}, h_{n}=0.150 \mathrm{~m}$, $d_{n d}=0.080 \mathrm{~m} d_{n g}=0.100 \mathrm{~m}, d_{i n}=0.020 \mathrm{~m}$ (Fig. 1). The mould internal surface is covered with a protective coating which is made from a water suspension of quartzite dust with $2 \mathrm{~mm}$ thickness.

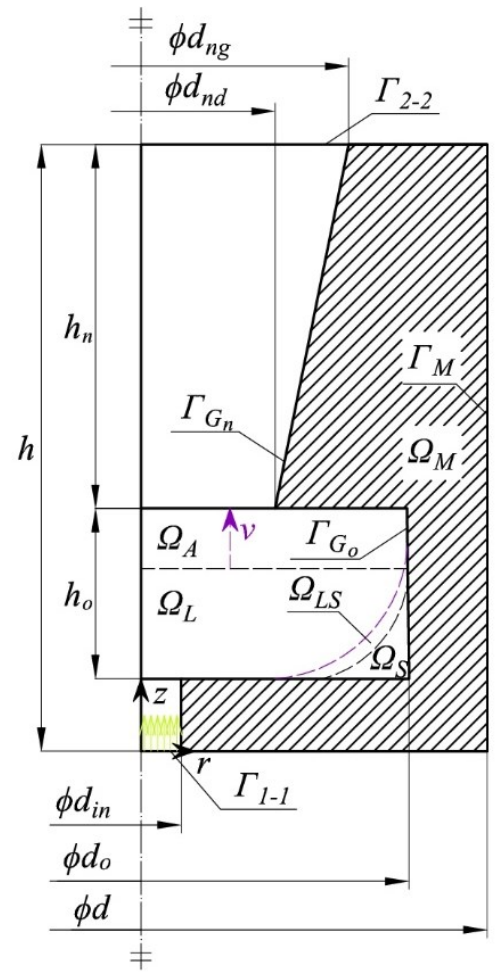

Fig. 1. Scheme and identification of sub-regions of the considered test problem

The numerical calculations were made for cast steel alloy. The thermophysical properties were taken from work [1,8-10] and are summarised in Table 1 for casting and 
Table 2 for other regions under consideration. The overheated metal with temperature $T_{\text {in }}=$ $1850 \mathrm{~K}$ was poured with the velocity $v_{i n}=0.1 \mathrm{~m} / \mathrm{s}$ into the mould with initial temperature $T_{M}$ $=350 \mathrm{~K}$. The remaining characteristic temperatures were equal to: $T_{A}=350 \mathrm{~K}, T_{a}=300 \mathrm{~K}$. The heat-transfer coefficient $(\alpha)$ between the mould and ambient was equal $\alpha_{M}=200$ $\mathrm{W} /\left(\mathrm{m}^{2} \mathrm{~K}\right)$. The thermal and flow phenomena occurring in the considered system in mutual influence were taken into account.

Table 1. Material properties of the casting - cast steel

\begin{tabular}{|c|c|c|}
\hline Material property & Liquid phase & Solid phase \\
\hline$\rho\left[\mathrm{kg} / \mathrm{m}^{3}\right]$ & 7300 & 7800 \\
\hline$c[\mathrm{~J} /(\mathrm{kgK})]$ & 830 & 644 \\
\hline$\lambda[\mathrm{W} /(\mathrm{mK})]$ & 23 & 45 \\
\hline$\mu[\mathrm{kg} /(\mathrm{ms})]$ & 0.006 & 10000 \\
\hline$\beta[1 / \mathrm{K}]$ & 0,00014 & \\
\hline \multicolumn{3}{|c|}{ Additional parameters } \\
\hline$T_{L}[\mathrm{~K}]$ & & \\
\hline$T_{S}[\mathrm{~K}]$ & & \\
\hline$L[\mathrm{~J} / \mathrm{kg}]$ & & \\
\hline
\end{tabular}

Table 2. Material properties used in the calculations for other regions

\begin{tabular}{|c|c|c|c|}
\hline Material property & Mould & Protective coating & Air \\
\hline \hline$\rho\left[\mathrm{kg} / \mathrm{m}^{3}\right]$ & 7200 & 1600 & 1.23 \\
\hline$c[\mathrm{~J} /(\mathrm{kgK})]$ & 600 & 1670 & 1006 \\
\hline$\lambda[\mathrm{W} /(\mathrm{mK})]$ & 42 & 0.3 & 0.024 \\
\hline$\mu[\mathrm{kg} /(\mathrm{ms})]$ & - & - & 0.000018 \\
\hline
\end{tabular}

The analysis of the casting process was performed using professional software (Fidap program), because it provides fast convergence of the numerical solution during mould filling simulation with liquid metal. The considered area was discretized by a mesh 5123 nodes, which define 4979 quadrilateral elements. The calculation process was stopped when the temperature in the casting decreased below the solidus temperature $\left(T_{S}\right)$. The study were carried out to determine whether the size of the riser was correctly selected for the solidifying the casting, so that it would be without shrinkage defects and its strength remained high.

\section{Results and discussion}

In this study, the heat transfer and fluid flow phenomena, proceeding in the mould cavity during filling and after the filling is finished until the completion of solidification, were analysed. The influences of liquid metal movements inside the mould cavity on the solidification kinetics of the casting were determined. Results of numerical calculation are shown in the form of velocity vectors and temperature fields in Figures 2-9. On the temperature fields, after filling completion of the mould cavity, the formation of the shrinkage cavity was observed by continuous tracking of the position of the solidus line in 
subsequent calculation stages of the casting solidification process (Figs 4-9). If this line does not close, the process of solidification proceeds correctly, whereas if this line closes, the solidifying casting is divided into smaller areas with a difficult inflow of liquid metal to them, which results in the creation of a shrinkage cavity in this place (Fig 9). In the casting system with a conical riser, the course of thermal and flow phenomena was analyzed. It was assessed whether the conical riser would fulfill its task, so that the cast was made without shrinkage defects.
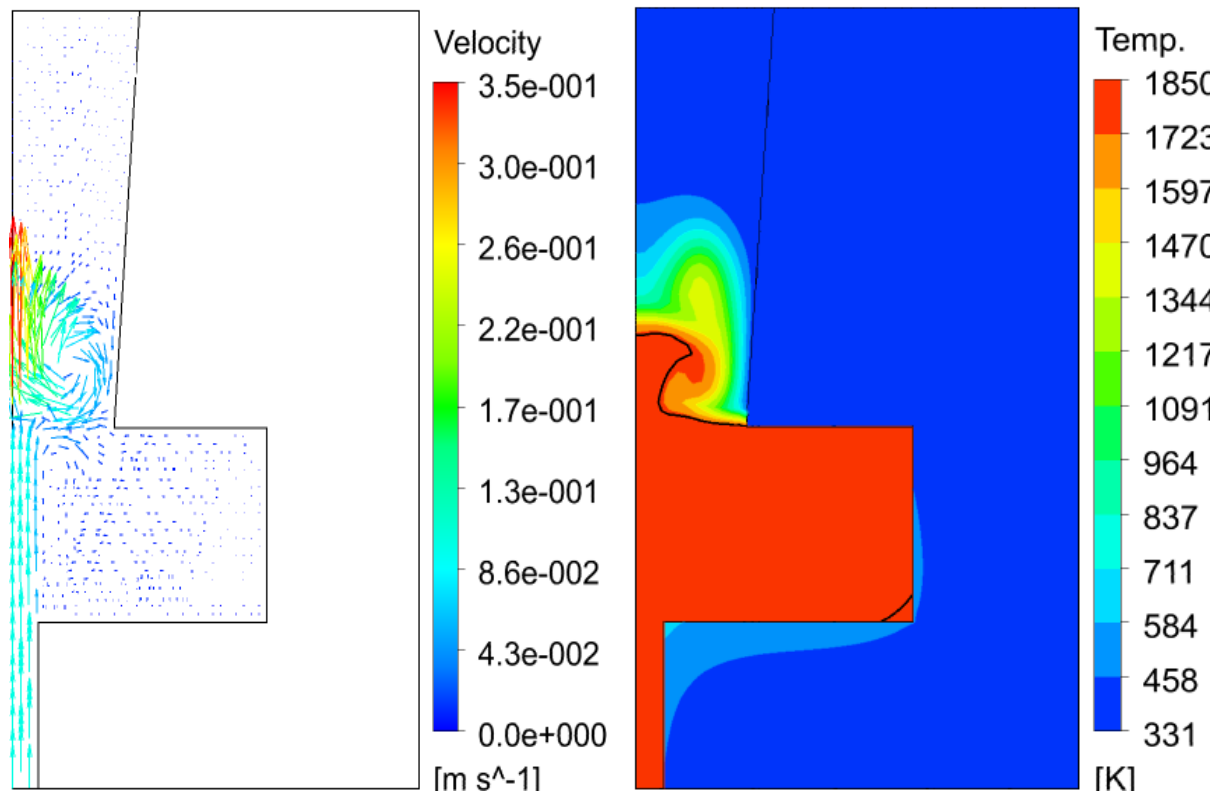

Fig. 2. Velocity and temperature fields during filling of the mould cavity with molten metal after time $71 \mathrm{~s}$, I variant
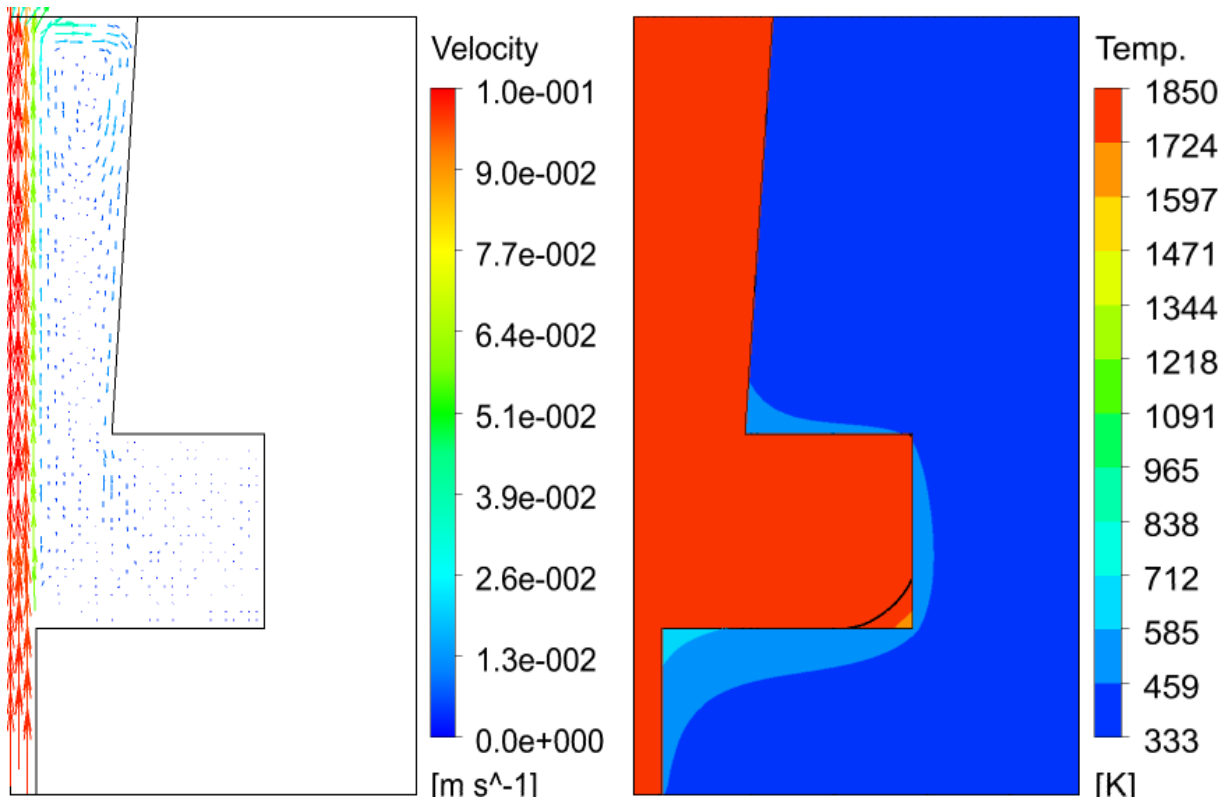

Fig. 3. Velocity and temperature fields during filling of the mould cavity with molten metal after time $105 \mathrm{~s}$, I variant 

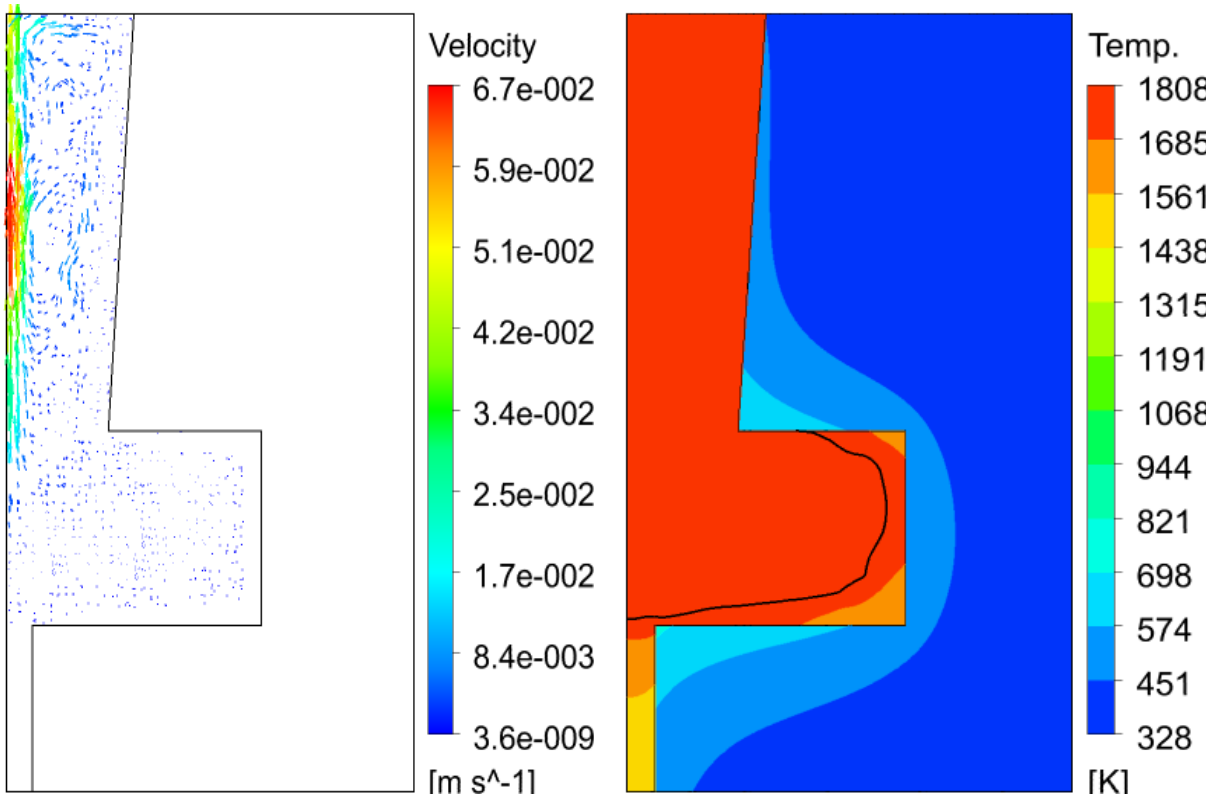

Fig. 4. Velocity and temperature fields after time 200 s, I variant
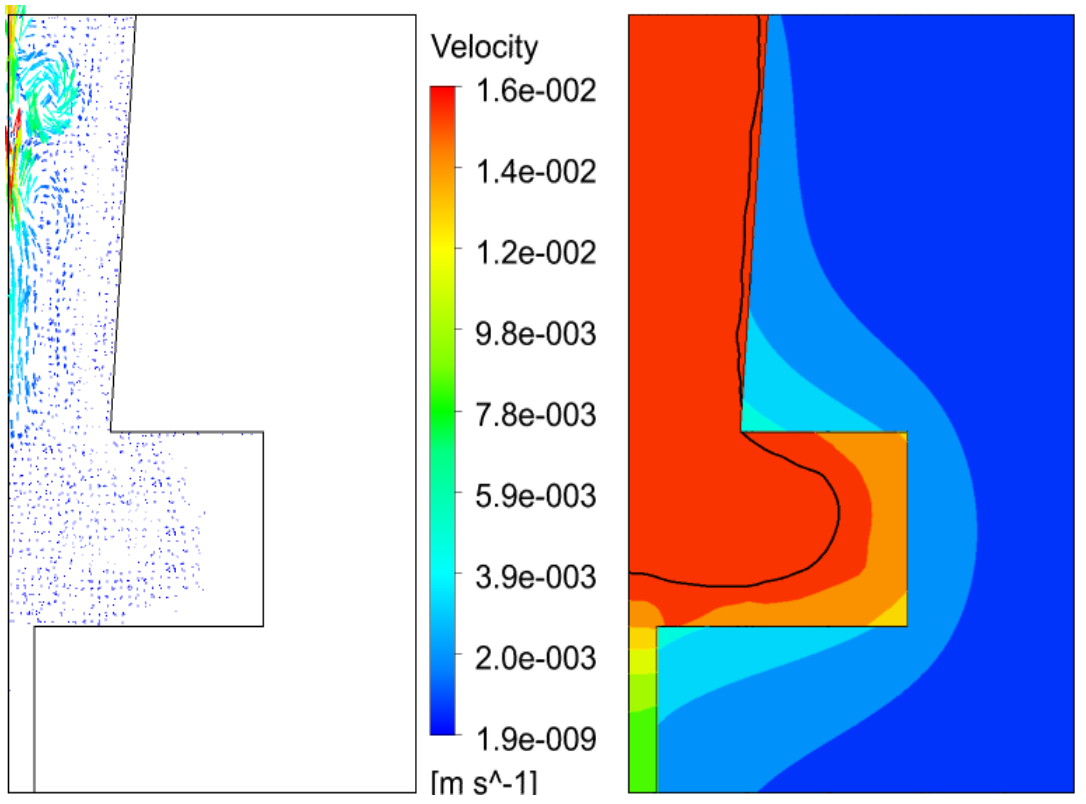

Temp.

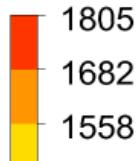

1435

1312

1189

1065

942

819

695

572

449

326

Fig. 5. Velocity and temperature fields after time $300 \mathrm{~s}$, I variant

The numerical calculations for two variants of the solidification process, with including or omitting the movements of molten metal, were made. The difference between these cases of solidification models are results from the number of differential equations used to describe of the casting solidification process. In the I variant: the numerical analysis was performed, included the filling process of the mould cavity with molten metal, fluid flow, convection motions and process of phase change. (Figs 2-7). This model is very complex. All differential equations (1-4) were used to obtain the fill state of the mold cavity, 
temperature fields, velocity and pressure. In variant II: the movement of molten metal has been neglected and it was assumed that the mould cavity is completely filled with molten metal at the pouring temperature as a precondition for calculating the solidification process. (Figs 8,9 ). This is a very simply mathematical model. In this model, only one differential equation (3) was used to obtain temperature fields.
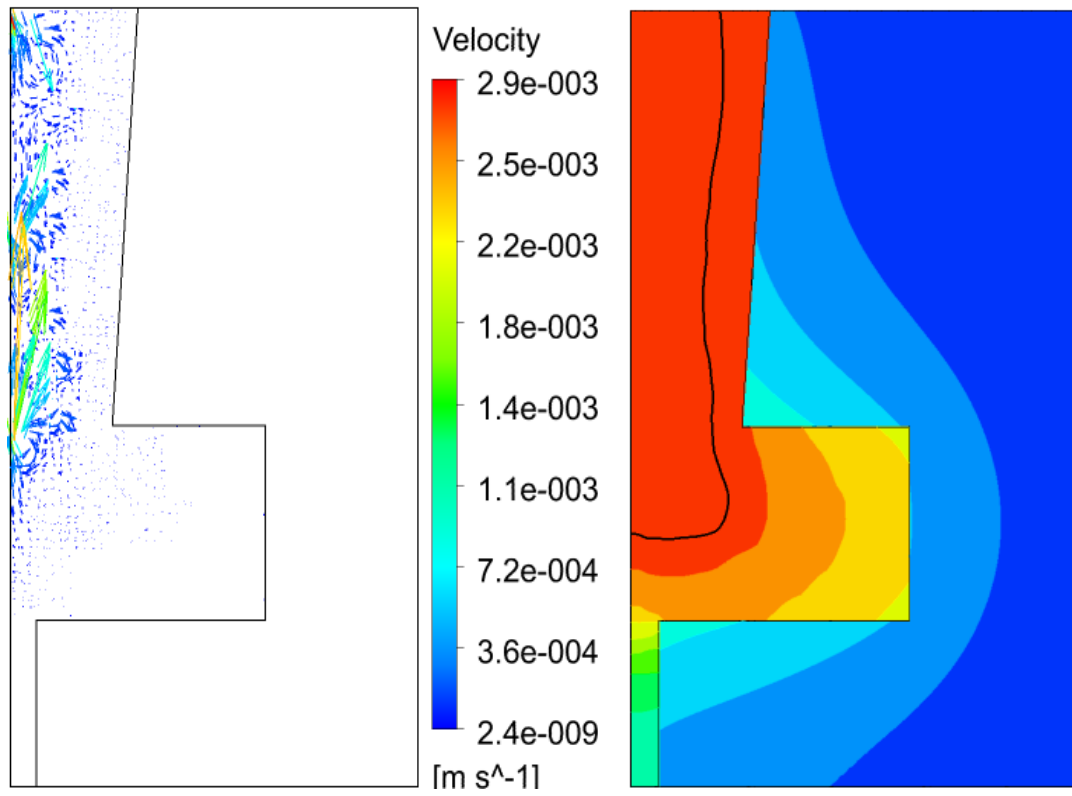

Temp.

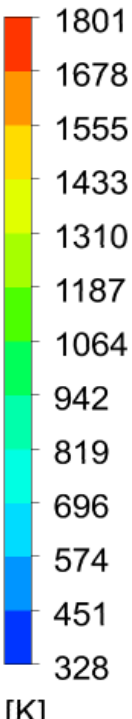

Fig. 6. Velocity and temperature fields after time $450 \mathrm{~s}$, I variant

a)

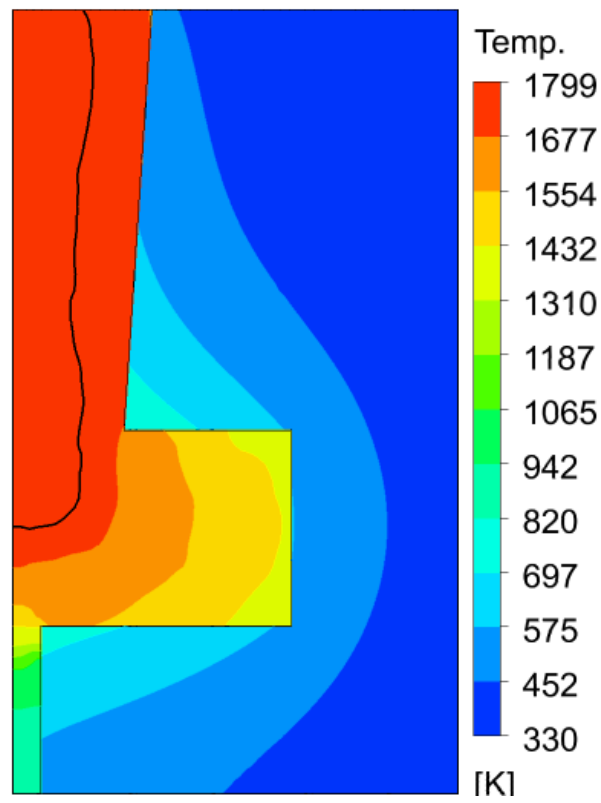

b)

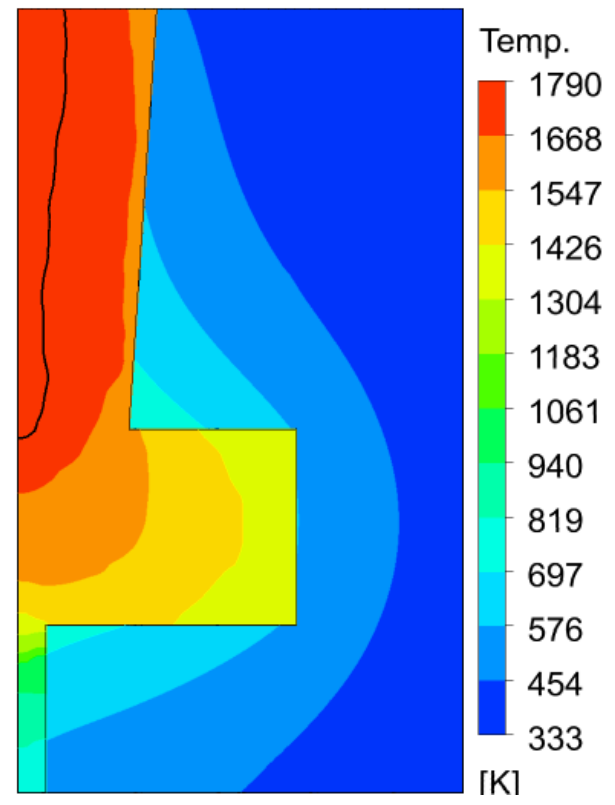

Fig. 7. Temperature fields after time: a) $490 \mathrm{~s}$, b) $560 \mathrm{~s}$, I variant 
a)

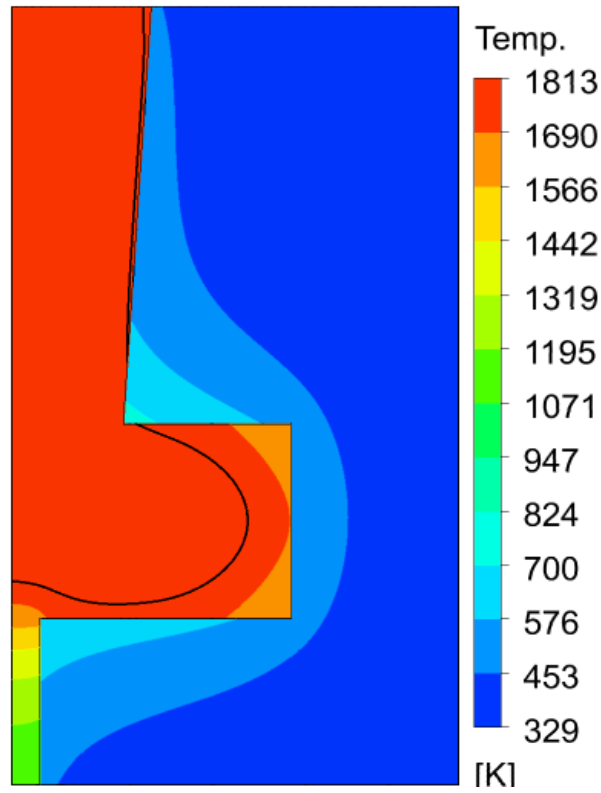

b)

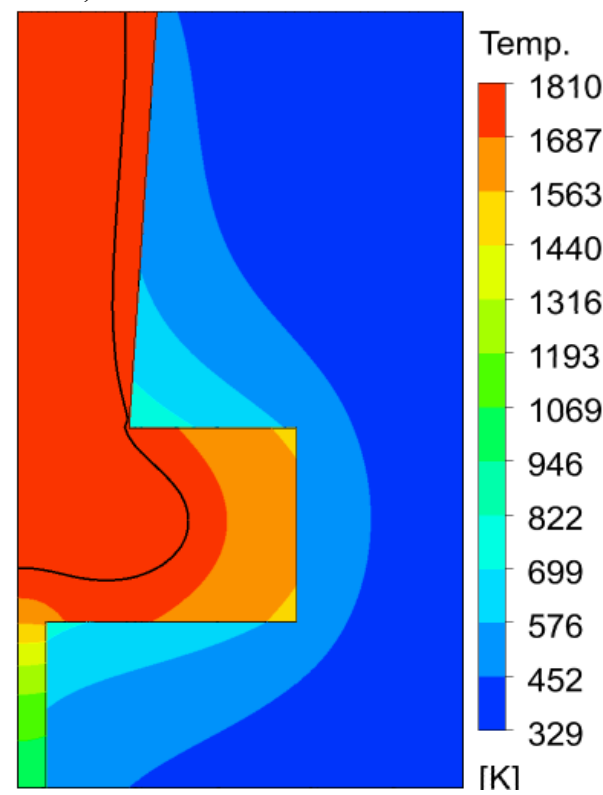

Fig. 8. Temperature fields after time: a) $200 \mathrm{~s}$, b) $300 \mathrm{~s}$, II variant

a)

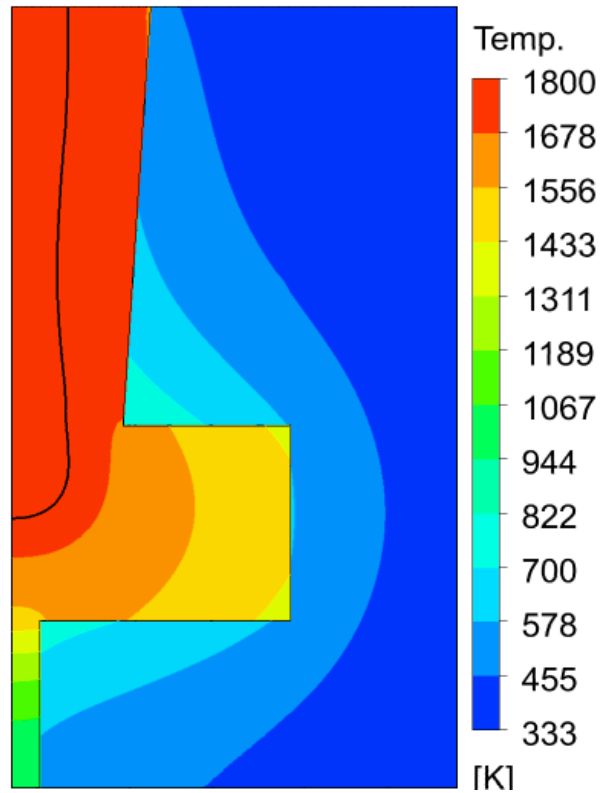

b)

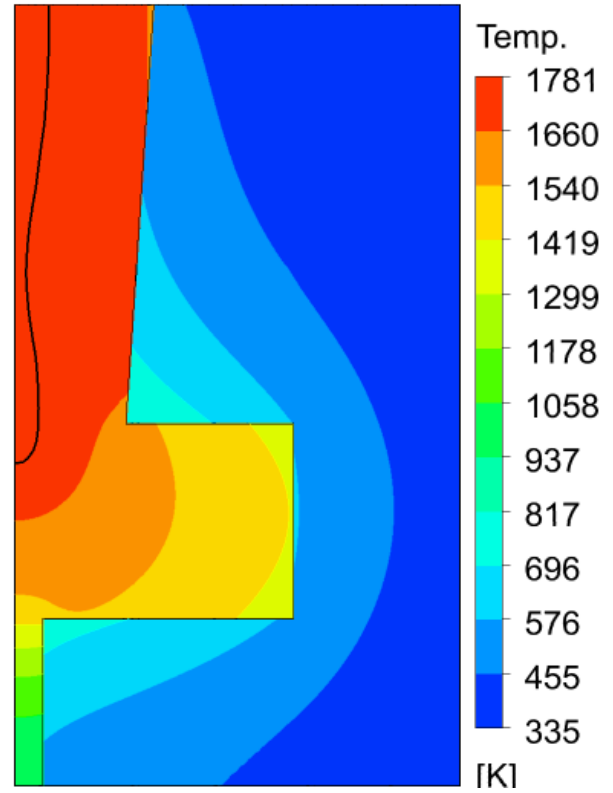

Fig. 9. Temperature fields after time: a) $450 \mathrm{~s}$, b) $490 \mathrm{~s}$, II variant

The influence of the types of solidification models on the results obtained from numerical calculations was analysed. The problem was solved using the finite element method. The performed researches allow to evaluate the state of casting and to indicate the critical areas in which shrinkage cavities may arise, what we are trying to avoid. 


\section{Conclusions}

This paper focuses mainly on the numerical simulations of the casting solidification process with taking into account the thermal and flow phenomena occurring in the mould cavity during its filling. The influence of molten metal motions and size of riser on solidification kinetics and on shrinkage cavity location in the end moment of casting solidification process was estimated. The mathematical model that takes into account the mutual influence of thermal and flow phenomena in the process of filling the cavity of the casting mould and after its completion, were formulated. Numerical calculations for two variants of the solidification process, with including or omitting the movements of molten metal, were made. The progression of thermal and flow phenomena was analysed in the system of the casting with conical riser obtaining velocity and temperature fields allowing follow the position of the solidus line in subsequent calculation stages (Figs 2-9). During filling of the mould cavity the solidification process took place only in the corners of mould cavity, where the movement of metal was small and the carrying away of heat was the most intensive (Figs 2,3). So the essential solidification process begins when the mold cavity is completely filled. This may be due to the small dimensions of the casting and the pouring of the too overheated metal. In the initial cooling period of the considered system, the continuous moving of the solidus line was observed, because there were favourable conditions for directional solidification (Figs 4-6, 8). Calculation of the solidification, with taking into account the molten metal motions, gives a picture of non-uniform increment of the solid phase with the possible presence of circulation moves (Figs 4-6). In the final solidification period of the casting-riser system, the closing of the solidus line and location of the shrinkage defect in the upper part of the casting was observed, if the solidification process was carried out without considering the movements of the liquid metal (Fig. 9b). This situation was not observed if the liquid phase movements were taken into account in the solidification process of the casting (Fig. 7b). In this case, the end of solidification occurred in the upper part of the riser, which is allowed because the riser with the formed shrinkage cavity is cut off and re-processed again. This proves that the conical riser fulfils its task and the casting has been made without shrinkage defects. So, taking into account the filling process and convective movements of the molten metal in numerical analysis, the casting conditions can be more accurately evaluated and the location of the shrinkage cavity can be determined more precisely.

\section{References}

1. K. Miłkowska-Piszczek, M. Korolczuk-Hejnak, An analysis of the influence of viscosity on the numerical simulation of temperature distribution as demonstrated by the CC process. Arch. Metal. Mater. 58 (4), 1263-1274 (2013)

2. L. Sowa, T. Skrzypczak, P. Kwiatoń, Analysis of temperature and velocity fields during filling of continuous casting mould. Arch Foundry Eng. 18(1), 115-118 (2018)

3. K. Grześkowiak, M. Wojciechowski, K. Sytek, The effect of the method of pouring liquid metal into mould on misrun formation in the castings made with lost-wax casting technology. Arch Mech Tech Autom. 33(4), 15-19 (2013)

4. R. Eriksson, L. Jonsson, P.G. Jönsson, Effect of entrance nozzle design on the fluid flow in an ingot mold during filling. ISIJ Inter. 44(8), 1358-1365 (2004)

5. L. Sowa., N. Sczygiol, Computer simulation of the filling and solidification of a gravity die casting, Solid. Met Alloys, 44(2), 329-334 (2000) 
6. P-H. Huang, C-J. Lin, Computer-aided modeling and experimental verification of optimal gating system design for investment casting of precision rotor. Int $\mathrm{J}$ Adv Manuf Technol 79(7-8), 997-1006 (2015)

7. R.W. Lewis, E.W. Postek, Z. Han, D.T. Gethin, A finite element model of the squeeze casting process. Int. J. Num Meth Heat Flow, 16(5), 539-572 (2006)

8. T. Skrzypczak, E. Węgrzyn-Skrzypczak, Three-dimensional numerical model of solidification with motion of the liquid phase. Arch Foundry Eng. 11(2), 127-132 (2011)

9. R. Dyja, E. Gawrońska, A. Grosser, A computer simulation of solidification taking into account the movement of the liquid phase. MATEC Web Conf. 157, 1-9 (2018)

10. T. Skrzypczak, E. Węgrzyn-Skrzypczak, L. Sowa, Numerical modeling of solidification process taking into account the effect of air gap. Appl Math Comput. 321, 768-779 (2018)

11. M. Perzyk, A. Kochański, P. Mazurek, K. Karczewski, Selected principles of feeding systems design: simulation vs industrial experience. Arch Foundry Eng. 14(4), 77-82 (2014)

12. Z. Saternus, W. Piekarska, M. Kubiak, T. Domański, L. Sowa, Numerical analysis of deformations in sheets made of X5CrNi18-10 steel welded by a hybrid laser-arc heat source. Proc. Eng. 136, 95-100 (2016) 